\title{
Conditionally Related to Intervention
}

National Cancer Institute

\section{Source}

National Cancer Institute. Conditionally Related to Intervention. NCI Thesaurus. Code C68618.

A characteristic used to qualify the adverse event as unclassified in term of its relation to the medical intervention. According to WHO causality assessment criteria of suspected adverse reactions it is applicable to clinical event, including laboratory test abnormality, reported as an adverse reaction, about which more data is essential for a proper assessment or the additional data are under examination. 